\title{
The Social Dimension Of Sustainable Development: Defining Tourism Social Sustainability
}

\author{
Agusta Ika Prihanti Nugraheni ${ }^{1}$, Tri Kuntoro Priyambodo ${ }^{1,2}$, Hendrie Adji Kusworo ${ }^{1}$, Bayu \\ Sutikno ${ }^{1}$ \\ \{agusta.nugraheni@ugm.ac.id ${ }^{1}$, mastri@ugm.ac.id² adjikusworo@ugm.ac.id ${ }^{3}$, \\ bayusutikno@ugm.ac.id $\left.{ }^{4}\right\}$ \\ ${ }^{1)}$ Tourism Studies Program, Graduate School of Universitas Gadjah Mada,Yogyakarta, Indonesia \\ ${ }^{2)}$ Center for Tourism Studies, Universitas Gadjah Mada, Yogyakarta, Indonesia
}

\begin{abstract}
The three dimension of Sustainable Tourism Development (STD), namely environmental, economic and social have been carried out with various approaches. Although these three dimensions influence each other and cannot stand on their own, and are assumed to be supportive to each other and compatible. However, most studies focus on the environmental and economic dimensions. The social dimension gains less attention and is difficult to attain and operationalise. To implement STD properly and balanced, it is necessary to explore the social dimension of STDs to obtain a clear agreement on the concept of social dimension in STD, especially from Indonesia's perspective. The purpose of this study is to explore the boundaries of social dimension of STD. This research is an exploratory study that aims to develop knowledge that is still new in nature and to provide direction for future research and also to fill gaps or shortcomings of the concept and definition of social aspects within the framework of STD using a systematic literature review. The result of the study is a concept of social dimension of Sustainable Tourism Development.
\end{abstract}

Keywords: Social dimension; Sustainable Tourism Development; Social Sustainability

\section{Introduction}

Sustainable Tourism Development (STD) become an important concept regarding development in tourism sector in the world. STD has three dimensions namely economic, social and environmental. Most studies related to STD were focusing on the environmental and economic dimension, while social dimension was tend to be overlooked. Although some scholars studied social dimension, there is still a problem to define and understand the fluid concept of social sustainability [1]. Social sustainability is a dynamic concept [2]. There is currently no agreement on how to define social sustainability, notably social sustainability in STD. Thus, social sustainability is still facing a conceptual chaos which compromises the term's utility [3]. 
Studies focusing on social sustainability is limited [2]. It is still on a practical understanding and become a political agenda and somewhat have not been grounded in theory [4]. Social sustainability currently is not seen as an equal dimension of STD but it is only seen as a part of economic dimensions or environmental dimensions [5], [6]. Although there are efforts to study and develop understanding of social sustainability, more of those attempted is not in the tourism discourse, but in other disciplines such as urban and regional planning, forestry, geography, etc. Therefore, there is still lack of understanding of social sustainability in STD. In achieving STD, we cannot neglect social dimension and only focuses on economic and environmental dimension. Thus, we still need to define a clear understanding and definition of social sustainability. A study is needed to explore the social dimension of STD starting with the formulation of clear definitions of STD's social dimension. Thus, the purpose of this study is to explore and developed the definition of social friendly tourism.

\section{Literature Review}

In 1987, the World Commission on Environment and Development (WCED) report to the United Nations (UN) which required that three dimensions have to be considered in Sustainable Development. Those three dimensions are social, ecological and economic conditions. Since then, social sustainability attained formal and international status [7], [8]. The concept of social sustainability is open and debatable, similar to the sustainable development concept [1]. According to Dempsey et.al [2], social sustainability is not a constant concept and it will change over time according to each location, culture or situation.

Aside from the limited number of studies related to social sustainability in general, notably, studies on social dimension of sustainability in tourism is still scarce. There have been efforts to take account social dimension into sustainability discourse in standard setters, planners and practitioners in many different disciplines, but those effort is somewhat less in tourism study. Those efforts mainly in other disciplines such as fair-trade certification [9] urban and regional planning [2], [10], [11], [12], conventional agriculture [13], [14], , organic agriculture [15], forest certification [16], [17], and corporate social and environmental management, reporting and responsibility [18], [19], [20].

Vallance, Harvey and Dixon [2] states that several consideration regarding social sustainability that arise from scholars focus on meeting basic needs and on "underdevelopment", which focus on transforming the negligent behavior of well-off people in the world and encouraging stronger environmental ethics. While, other scholar focus on sustaining particular way of living in keeping certain socio-cultural traditions

\section{Research Method}

Systematic literature review is used in this study to obtain knowledge regarding the definition and understanding of social dimension of STD. Systematic literature review can be used to respond to the early stages of the understanding of certain issues, which is social dimension of sustainable tourism development in this case and to describe complex, multidisciplinary and fragmented condition that define social dimension of STD [21], [22], [23]. This method offers a comprehensiveness in the search for relevant publication on a certain theme or issue [24]. Several steps will guide a synthesis and critical appraisal of the 
literature and it is efective to reveal what is known and what is not yet known about a subjetcs and in mapping out the breadth of a field [24], [25]. This method is also useful for coping with a knowledge base that is diverse and transdisciplinary [21], [22]. There are three steps in systematic literature review, which are (1) defining search criteria, (2) filtering, and (3) review and categorization [24].

\section{Result and Discussion}

Social sustainability is an open and debatable concept similar to the general concept of sustainable development [1]. The concept of social sustainability is neither an absolute nor a constant and it will change over time in a place, therefore it has to be considered as a dynamic concept [2]. Colantonio and Dixon [6] argued that literatures that focuses on social sustainability is limited to the extent that a comprehensive study of this concept is still scarce. Moveover, the approaches to the social sustainability concept, according to Littig and Grießler [4] is still on a practical understanding of plausibility and current political agendas and have not been grounded on theory. OECD [26] also points out that social sustainability did not receive the same manners as a constitutive component of sustainable development but it is treated as a part of social implications of enviromental politics [4].

There is no single definition of social sustainability because the dynamic nature of it. Athough, there are already several efforts in defining or suggesting typologies and framework of social sustainability. Most of social sustainability definitions rather being general, it was developed according to discipline-specific criteria or study perspectives. Some of the definitions offer conceptual definitions, while others offer key themes of topic that portray social issues relevant to the sustanability discourse [27].

Table 1. Conceptual Definition

\begin{tabular}{|c|l|l|}
\hline No & \multicolumn{1}{|c|}{ Authors } & \multicolumn{1}{|c|}{ Conceptual Definition or Key Themes } \\
\hline 1. & $\begin{array}{l}\text { Barbier (1987) } \\
\text { and Konning } \\
\text { (2002) }\end{array}$ & $\begin{array}{l}\text { the importance of maintaining social values such as equity, culture } \\
\text { and social justice are the focus of social sustainability }\end{array}$ \\
\hline 2. & Sachs (1999) & $\begin{array}{l}\text { basic values of equity and democracy become the foundation or } \\
\text { building blocks of social sustainability }\end{array}$ \\
\hline 3. & $\begin{array}{l}\text { Harris and } \\
\text { Goodwin (2001) }\end{array}$ & $\begin{array}{l}\text { A socially sustainable system has to achieve fairness in distribution } \\
\text { and opportunity, satisfactory establishment of social services, } \\
\text { including education and health, gender equity, political } \\
\text { accountability and participation }\end{array}$ \\
\hline 4. & $\begin{array}{l}\text { McKenzie } \\
\text { (2004) }\end{array}$ & $\begin{array}{l}\text { Social sustainability is a condition and a process which is a } \\
\text { positive, life-enhancing condition within communities, and a } \\
\text { process with that can achieve that condition } \\
\text { Communities that are socially sustainable are equitable, diverse, } \\
\text { connected, and democratic and provide a good quality of life }\end{array}$ \\
\hline 5. & $\begin{array}{l}\text { Littig and } \\
\text { Grießler (2005) }\end{array}$ & $\begin{array}{l}\text { undine the importance of 'work' and 'needs' in social } \\
\text { sustainability and also emphasize the relations between nature and } \\
\text { society by stating that 'Social sustainability is given, if work within } \\
\text { a society and the related institutional arrangements satisfy an } \\
\text { extended set of human needs [and] are shaped in a way that nature } \\
\text { and its reproductive capabilities are preserved over a long period of } \\
\text { time and the normative claims of social justice, human dignity and }\end{array}$ \\
\hline
\end{tabular}




\begin{tabular}{|l|l|l|l|}
\hline No & \multicolumn{1}{|c|}{ Authors } & \multicolumn{1}{|c}{ Conceptual Definition or Key Themes } \\
\hline 6. & $\begin{array}{l}\text { UNEP and } \\
\text { UNWTO (2005) }\end{array}$ & $\begin{array}{l}\text { Social sustainability requires supporting human rights, equal } \\
\text { opportunities, equal distributions of benefits and the poverty } \\
\text { alleviation as well as improving the livelihood of local } \\
\text { communities, maintaining and strengthening the community's life } \\
\text { support system, preserving traditional cultures and preventing }\end{array}$ \\
\hline exploitation.
\end{tabular}

According to Sachs [28], social sustainability 'must rest on basic values of equity and democracy'. While Barbier [29] and Konning [30] suggest that the focus of social sustainability is on the importance of maintaining social values such as equity, culture and social justice. Littig and Grießler [4] emphasis the importance of 'work' and 'needs' in social sustainability and also underline the relations between nature and society by proclaiming that "Social sustainability is given, if work within a society and the related institutional arrangements satisfy an extended set of human needs [and] are shaped in a way that nature and its reproductive capabilities are preserved over a long period of time and the normative claims of social justice, human dignity and participation are fulfilled."

Social sustainability definitions by UNEP and UNWTO [31] entails supporting human rights, equal opportunities, equal distributions of benefits and the poverty alleviation as well as improving the livelihood of local communities, maintaining and strengthening the community's life support system, preserving traditional cultures and preventing exploitation. 
According to Vallance, Perkins and Dixon [3], the evolution of a particular branch of sustainable development related with its social dimensions and implications - social sustainability - at the same time as highlighting ways in which the idea still associates with broader bio-physical environmental and economic issues and challenges. They studied the work carried out on the social dimensions of social sustainability development and attempts to define, organize and operationalize' social sustainability and summaries these varied studies. Vallance, Perkins and Dixon study [3] summaries into threefold schema of social sustainability's which are (a) 'development sustainability' addressing basic needs, the creation of social capital, justice, equity and so on; (b) 'bridge sustainability' concerning changes in behavior so as to achieve bio-physical environmental goals; and (c) 'maintenance sustainability' referring to the preservation - or what can be sustained - of socio-cultural characteristic in the face of change and the ways in which people actively embrace or resist those changes. Vallance, Perkins and Dixon [3] illustrated the difference between the threefold schema of social sustainability's of housing.

Harris and Goodwin [32 suggest that a system that is socially sustainable have to achieve fairness in distribution and opportunity, satisfactory establishment of social services, including education and health, gender equity, political accountability and also participation [34]. In addition, Dillard et. al [33] encapsulate several social sustainability concept from several scholars which used a working definition of the social aspect of sustainability. In understanding social aspect of sustainability, we should consider it as "the process that generate social health and well-being now and in the future" and also as "social institutions that facilitate environmental and economic sustainability now and for the future" [33], [34]. McKenzie [35] consider social sustainability as a condition and a process. Social sustainability is an "a positive, life-enhancing condition within communities, and a process with that can achieve that condition" [35], [36]. Moreover, McKenzie [35] stated that the indicators of social sustainability consists of equity, diversity, interconnectedness systems and structure, quality of life and democracy and govenment. Therefore, a socially sustainable communities are equitable, diverse, connected, and democratic and provide a good quality of life [35]

Colantonio and Dixon [6] stated that social sustainability related to how societies, communities and individuals live with each other and intend to carry out the objectives of the chosen development models while also considering the physical boundaries of their places and planet earth altogether. The development of social sustainablity at a more operational comes from actions in fundamental thematic areas, consist of the social sphere of individuals and societies, from capacity building and development of skills to enviromental and spatial imbalances [6]. Thus, it can be understood that social sustainability unifies the traditional social policy themes and notions, for instance health and equity with emerging issues in relation to participation, needs, social capital, the economy, the environment and also the principles of happiness, well being and quality of life [6]. Magis and Shinn [8] suggest four universal principles covering social sustainability which are Human well-being, Equity, Democratic government and Democratic civil society. Cuthill's [11] studies developed a social sustainability frameworks that includes social justice and equity, social infrastructure, engaged governance and social capital. The Millennium Development Goals or MDGs [37], proclaimed that social sustainability is related to ending extreme poverty and hunger, providing universal primary eduction, promoting equality of gender and women empowerment, improving maternal health, reducing child mortality, combating HIV/AIDS and malaria, encouraging environmental sustainability and global partnership for develompent. Those aspects, represent human needs and basic rights that should be enjoyed by every person [37]. 
Tourism is a complex discipline and industry, which incorporate many disciplines in order to function and operate properly. Therefore the selected wide set of definitions gives consideration in drawing conclusions on the significant concept and definitions of tourism social sustainability. Most of the definitions consider equity, social fairness, community participation, human well-being and quality of life good governance in describing social sustainability. Those themes can be elaborate into details aspects. The general concept of social sustainability is presented by Colantonio and Dixon [6], which that "social sustainability related to how societies, communities and individuals live with each other and intend to carry out the objectives of the chosen development models while also considering the physical boundaries of their places and planet earth altogether". Therefore, based on this definition, it can be conluded that the tourism social sustainability is a condition and a process within tourism that related to how tourism societies, communities, individuals and governments live with each others and aimed to carry out the objectives of sustainable tourism models and also considering the physical boundaris of the tourism destination and planet earth as a whole. This definition emphasis on the relationship between societies, communities, individuals and governments to achieve a social condition that gives fairness and good quality of life in tourism industry. Others definitions offer key themes or aspects of topic that portray social issues relevant to the sustanability discourse. Further research, therefore, is needed to validate the the aspects of social sustainability in order to develop a well-defined social sustainability definitions in sustainable tourism development.

\section{Conclusion}

It can be concluded that social sustainability discourse is still limited in Sustainable Tourism Development discussions. Therefore, in order to define and understand the concept of social sustainability, we have to explore other disciplines, such as urban and regional planning, politics, geography, forestry, CSR and business. Several scolars did not define social sustainability into a clear definition, others focusing on the aspect that determine a social sustainability process and goals. This paper conludes that the tourism social sustainability is a condition and a process within tourism that related to how tourism societies, communities, individuals and governments live with each others and aimed to carry out the objectives of sustainable tourism models and also considering the physical boundaris of the tourism destination and also the planet earth as a whole. This definition emphasis on the proces and the relationship between societies, communities, individuals and governments to achieve a social condition that gives fairness and good quality of life in tourism industry. It also describe the social condition that are desired in developing tourism.

\section{References}

[1] M. Boström, "A missing pillar? Challenges in theorizing and practicing social sustainability: introduction to the special issue“, Sustainability: Science, Practice and Policy, 8(1), 3-14, 2012, doi: 10.1080/15487733.2012.11908080

[2] N. Dempsey, G. Bramley, S. Power and C. Brown, C, "The social dimension of sustainable development: defining urban social sustainability“, Sustainable Development, 19, 289-300, 2011. 
[3] S. Vallance, H.C. Perkins and J.E. Dixon, "What is social sustainability?a clarification of concept", Geoforum, 42, 342-348, 2011

[4] B. Littig and E. Grießler, (2005), "Social sustainability: a catchword between political pragmatism and social theory“, International Journal of Sustainable Development 8(12), 65-79, 2005.

[5] A. Colantonio, "Social sustainability: an exploratory analysis of its definition, assessment methods, metrics and tools“, EIBURS Working Paper Series, July, 2007.

[6] A. Colantonio and T. Dixon, Measuring socially sustainable urban regeneration in Europe, Oxford Institute for Sustainable Development (OISD) School of the Built Environment Oxford Brookes University, 2009.

[7] World Commission on Environment and Development. Our Common Future. United Nations, 1987.

[8] K. Magis, and C. Shinn, "Emergent principles of social sustainability", in J. Dillard, V. Dujon, and M. King (Eds.), Understanding the Social Dimension of Sustainability, 1544, New York: Routledge, 2009.

[9] P. Taylor, "In the market but not of it: fair trade coffee and Forest Stewardship Council certification as market-based social change", World Development, 33(1), 129-147, 2004.

[10] M. Schlossberg and A. Zimmerman, "Developing statewide indices of environmental, economic, and social sustainability: a look at Oregon and the Oregon benchmarks". Local Environment 8(6), 641-660, 2003.

[11] M. Cuthill, "Strengthening the "social" in sustainable development: developing a conceptual framework for social sustainability in a rapid urban growth region in Australia“, Sustainable Development 18(6), 362-373, 2009.

[12] M. Davidson, "Social sustainability: a potential for politics?", Local Environment, 14(7), 607-619, 2009.

[13] H. Nordström Källström and M. Ljung, M, Social sustainability and collaborative learning. Ambio 34(4-5), 376-382, 2005

[14] F. Mancini, A. Termorshuizen, J. Jiggins, and A. van Bruggen, A, "Increasing the environmental and social sustainability of cotton farming through farmer education in Andhra Pradesh, India“. Agricultural Systems 96(1-3), 16-25, 2008.

[15] A. Shreck, C. Getz, and G. Feenstra, " Social sustainability, farm labor, and organic agriculture: findings from an exploratory analysis“, Agriculture \& Human Values 23(4), 439-449, 2006.

[16] D. Klooster, "Standardizing sustainable development? The Forest Stewardship Council's plantation policy review process as neoliberal environmental governance“, Geoforum 41(1), 117-129, 2010.

[17] M. Boström, "The problematic social dimension of sustainable development: the case of the Forest Stewardship Council“", International Journal of Sustainable Development \& World Ecology Published Online: July 13, 2011.

[18] S. Sharma, and A. Ruud, A, "On the path to sustainability: integrating social dimensions into the research and practice of environmental management", Business Strategy and the Environment 12(4), 205-214, 2003.

[19] J. Bebbington and J. Dillard, "Social sustainability: an organizational-level analysis". In J. Dillard, V. Dujon, \& M. King (Eds.), Understanding the Social Dimension of Sustainability, 157-173, New York: Routledge, 2009. 
[20] D. Brown, J. Dillard and S. Marshall, "Triple bottom line: a business metaphor for a social construct. In J. Dillard, V. Dujon, \& M. King (Eds.)“, Understanding the Social Dimension of Sustainability, 211-229, New York: Routledge, 2009.

[21] B. Farrell, and L. Twining-Ward, L. "Reconceptualizing tourism. Annals of Tourism Research, 31(2), 274-295, 2004.

[22] A. A. Pomering, G. I. Noble, and L. Johnson, L, Conceptualising a contemporary marketing mix for sustainable tourism. Journal of Sustainable Tourism, 19(8), 953969, 2011.

[23] C. Tölkes, "Sustainability communication in tourism - A literature review", Tourism Management Perspective, 27, 10-21, 2018.

[24] M. Petticrew, and H. Roberts, Systematic reviews in the social sciences: A practical guide. Malden, MA: Blackwell Publishing, 2006.

[25] C. Pickering and J. Byrne, "The benefits of publishing systematic quantitative literature reviews for $\mathrm{PhD}$ candidates and other early career researchers“. Higher Education Research and Development, 33(3), 534-548, 2014.

[26] OECD, OECD Guidelines for Multinational Enterprises, Paris: OECD Publishing, 2008.

[27] The UNSD Website, http://www.un.org/esa/dsd/susdevtopics/sdt_index.shtml, 2010.

[28] I. Sachs, 1999, "Social sustainability and whole development. In: Becker, E., Jahn, T. (Eds.), Sustainability and the Social Sciences. Zed Books and UNESCO, New York, 25-36, 1999.

[29] E.B. Barbier, "The concept of sustainable economic development", Environmental Conservation, 14 (2), 101-110, 1987, DOI: 10.1017/S0376892900011449

[30] J. Koning, "Social Sustainability in a globalizing world: context, theory and methodology explored", In More on MOST: Proceedings of an Expert Meeting, Rinsum HJ van, Ruijter A de, Kazancigil A, Alagh YK, Genov N, Koning J, Siebers H, Unesco Centre: Amsterdam, 2002.

[31] UNWTO, "Sustainable development of tourism: definition", 2005. Available: http://sdt.unwto.org/content/about-us-5

[32] J.M. Harris, A.W. Timothy, K. P. Gallagher and N.R. Goodwin (eds), A Survey of Sustainable Development: Social and Economic Dimensions, Washington, D.C., Island Press, 2001.

[33] J. Dillard, V. Dujon and M. King (Eds.), Understanding the Social Dimension of Sustainability. New York: Routledge, 2009.

[34] K. Thomsen and M.C. King, "Working out Social Sustainability on the Ground", n J. Dillard, V. Dujon, and M. King (Eds.), Understanding the Social Dimension of Sustainability, 199-210, 2009

[35] S. McKenzie, "Social sustainability: towards some definitions". In Hawke Research Institute Working Paper Series, No 27. Magill, South Australia: Hawke Research Institute, University of South Australia, 2004.

[36] W. B. Messer and K. Kecskes, "Social capital and community: university partnership", in J. Dillard, V. Dujon, and M. King (Eds.), Understanding the Social Dimension of Sustainability, 248-263, New York: Routledge, 2009.

[37] C. Weingaertner, and A. Moberg, "Exploring Social Sustainability: Learning from Perspectives on Urban Development and Companies and Products", Sustainable Development, 2011, doi: http://dx.doi.org/10.1002/sd.536 